\title{
Effects of linagliptin and liraglutide on glucose- and angiotensin II-induced collagen formation and cytoskeleton degradation in cardiac fibroblasts in vitro
}

\author{
Xian-wei WANG ${ }^{1,2, *}$, Fen-xi ZHANG ${ }^{3}$, Fen YANG ${ }^{1}$, Zu-feng DING ${ }^{2}$, Nidhi AGARWAL ${ }^{2}$, Zhi-kun GUO ${ }^{1}$, Jawahar L MEHTA ${ }^{2}$ \\ ${ }^{1}$ Henan Key Laboratory of Medical Tissue Regeneration, Xinxiang Medical University, Xinxiang 453003, China; ${ }^{2}$ Central Arkansas \\ Veterans Healthcare System, and the Division of Cardiology, University of Arkansas for Medical Sciences, Little Rock, AR, USA; ${ }^{3}$ College \\ of Life Science, Henan Normal University, Xinxiang 453007, China
}

\begin{abstract}
Aim: Glucagon-like peptide-1 (GLP-1) agonists and dipeptidyl peptidase-4 (DPP-4) inhibitors can not only lower blood glucose levels, but also alleviate cardiac remodeling after myocardial ischemia and hypertension. In the present study, we investigated the effects of a DPP-4 inhibitor (linagliptin) and a GLP-1 activator (liraglutide) on glucose- and angiotensin II (Ang II)-induced collagen formation and cytoskeleton reorganization in cardiac fibroblasts in vitro, and elucidated the related mechanisms.

Methods: Cardiac fibroblasts were isolated from the hearts of 6-week-old C57BL/6 mice, and then exposed to different concentrations of glucose or Ang II for $24 \mathrm{~h}$. The expression of fibrotic signals (fibronectin, collagen-1, -3 and -4), as well as ERK1/2 and NF-kB-p65 in the fibroblasts was examined using Western blotting assays. F-actin degradation was detected under inverted laser confocal microscope in fibroblasts stained with Rhodamine phalloidin.

Results: Glucose (1-40 mmol/L) and Ang II (10 $\left.{ }^{-8}-10^{-5} \mathrm{~mol} / \mathrm{L}\right)$ dose-dependently increased the expression of fibronectin, collagens, phosphoERK1/2 and phospho-NF-KB-p65 in cardiac fibroblasts. High concentrations of glucose ( $\geq 40 \mathrm{mmol} / \mathrm{L})$ and Ang II $\left(\geq 10^{-6} \mathrm{~mol} / \mathrm{L}\right) \mathrm{caused} \mathrm{a}$ significant degradation of F-actin (less assembly F-actin fibers and more disassembly fibers). ERK1/2 inhibitor U0126 (10 $\mu \mathrm{mol} / \mathrm{L})$ and NF-KB inhibitor JSH-23 (10 $\mathrm{mol} / \mathrm{L})$ both markedly suppressed glucose- and angiotensin Il-induced fibronectin and collagen expressions in cardiac fibroblasts. Furthermore, pretreatment with liraglutide (10-100 nmol/L) or linagliptin (3 and $30 \mathrm{nmol} / \mathrm{L})$ significantly decreased glucose- and Ang II-induced expression of fibrotic signals, phospho-ERK1/2 and phospho-NF-kB-p65 in cardiac fibroblasts. Moreover, pretreatment with liraglutide $(30 \mathrm{nmol} / \mathrm{L})$ or liraglutide $(100 \mathrm{nmol} / \mathrm{L})$ markedly inhibited glucose-induced F-actin degradation, however, only liraglutide inhibited Ang II-induced F-actin degradation.

Conclusion: Linagliptin and liraglutide inhibit glucose- and Ang II-induced collagen formation in cardiac fibroblasts via activation of the ERK/NF-KB/pathway. Linagliptin and liraglutide also markedly inhibit glucose-induced F-actin degradation in cardiac fibroblasts, but only liraglutide inhibits Ang II-induced F-actin degradation.
\end{abstract}

Keywords: cardiac remodeling; cardiac fibroblast; glucose; angiotensin II; collagen formation; cytoskeleton organization; linagliptin; liraglutide Acta Pharmacologica Sinica (2016) 37: 1349-1358; doi: 10.1038/aps.2016.72; published online 8 Aug 2016

\section{Introduction}

A novel milestone in the treatment of pre-diabetic or frankly diabetic patients is the development of dipeptidyl peptidase 4 (DPP4) inhibitors which prevent the degradation of glucagon-like peptides (GLP-1). DPP-4 inhibitors have been widely used to treat patients with type II diabetes mellitus. Application of DPP-4 inhibitors has been shown to improve insulin resistance in animal models ${ }^{[1]}$. Recent studies have shown that DPP-4 inhibitors have effects beyond just lowering blood sugar ${ }^{[2]}$. These agents

\footnotetext{
*To whom correspondence should be addressed.

E-mail xwang2@uams.edu

Received 2016-02-01 Accepted 2016-05-31
}

have immune regulatory and anti-inflammatory effects which may influence cardiac performance in pathological states ${ }^{[2]}$.

It is known that type II diabetes enhances the risk of cardiac complications $^{[3]}$. Some studies have demonstrated that DPP-4 inhibitors exert cardioprotective effects in animals with diabetes as well as in patients with type II diabetes ${ }^{[3-5]}$. Lenski et al observed that sitagliptin inhibited cardiac hypertrophy, fibrosis and the expression of transforming growth factor $\beta$ (TGF$\beta$ ), without affecting plasma glucose concentrations in $\mathrm{db} / \mathrm{db}$ diabetic mice ${ }^{[3]}$. Picatoste et al reported that pre-treatment with sitagliptin reduced diabetes-associated cell apoptosis, cardiac fibrosis and hypertrophy in the heart of Goto-Kakizaki (GK) rats with diabetes ${ }^{[4]}$. Connelly et al showed that sitagliptin 
improved left ventricular compliance, increased endothelial cell density, reduced myocyte hypertrophy, and inhibited cardiac fibrosis without affecting plasma glucose in diabetic rats with experimental myocardial infarction ${ }^{[5]}$. These animal studies suggest that the DPP-4 inhibitors exert cardioprotective effect in multiple settings, and some of their effects are independent of decrease of plasma glucose levels. Further, pooled analyses of clinical studies and smaller mechanistic studies showed that DPP-4 inhibitors might exert cardiovascular benefits in patients with type II diabetes ${ }^{[6,7]}$.

A recent study indicated that DPP-4 inhibitor linagliptin could significantly reduce infarct size $(\approx 17 \%)$ and myocardial fibrosis $(\approx 30 \%)$ following myocardial ischemia/reperfusion in rats ${ }^{[8]}$, but the underlying mechanism(s) remain(s) unclear. Of note, the reduction in infarct size and myocardial fibrosis was not sufficient to improve cardiac function ${ }^{[8]}$. Chinda et al also reported that another DPP-4 inhibitor vildagliptin could decrease effective refractory period dispersion, reduce ventricular premature contractions and infarct size, and attenuate cardiac mitochondrial dysfunction in hearts of pigs during ischemia/reperfusion injury ${ }^{[9]}$. Of note, the cardioprotective effects of vildagliptin were associated with a reduction in reactive oxygen species $(\mathrm{ROS})^{[9]}$.

Fibroblasts are one of the essential cellular components of remodeling process and the increase in their activity results in cardiac fibrosis and subsequent cardiac remodeling. The effects of linagliptin on collagen formation and cytoskeleton organization in cardiac fibroblasts have not been studied. The aim of the present study was to investigate the effect of DPP-4 inhibitor linagliptin and GLP-1 activator liraglutide on collagen formation and cytoskeleton organization in cardiac fibroblasts and the related mechanisms. Cardiac fibroblast activation was induced by two different stimuli-glucose and angiotensin II (Ang II).

\section{Materials and methods}

\section{Isolation and culture of cardiac fibroblasts}

Cardiac fibroblasts were isolated from the hearts of 6-weekold C57BL/ 6 mice as per recently published protocol ${ }^{[10]}$. In brief, the mice were sacrificed under anesthesia with sodium pentobarbital $(80 \mathrm{mg} / \mathrm{kg}$, ip) and their hearts were quickly collected and put on ice. After opening the chambers with sterile scissors, the hearts were dipped in $70 \%$ ethanol for $30 \mathrm{~s}$ to kill endothelial cells. Then, the ventricular tissue was isolated, minced into small pieces in phosphate-buffered saline (PBS), and then digested with $0.25 \%$ trypsin $/ 100 \mathrm{U} / \mathrm{mL}$ collagenase. The digestion process was repeated until the tissues were completely digested. Cell suspension was collected and centrifuged (1000 rounds per minute for $6 \mathrm{~min}$ ), and the isolated cells were re-suspended in fibroblast basal medium (supplemented with $10 \mathrm{~mL}$ FBS, $7.5 \mathrm{mmol} / \mathrm{L}$ L-glutamine, 2.5 ng rh-FGF- $\beta, 2.5 \mu \mathrm{g}$ rh-insulin, $25 \mu \mathrm{g}$ ascorbic acid, and 0.5 $\mu \mathrm{g}$ hydrocortisone) (ATCC, Manassas, VA, USA) and seeded into the flasks. One hour after plating, the unattached cells were discarded and the attached cells were cultured in fibroblast basal medium in a cell culture incubator at $37^{\circ} \mathrm{C}$ under $5 \% \mathrm{CO}_{2}$. Passage 3-5 cells were used in the following experiments. The use of animals was approved by the local animal care committee and conformed to the Guide for the Care and
Use of Laboratory Animals published by the US National Institutes of Health.

\section{Study protocol}

Cardiac fibroblasts were exposed to different concentrations of glucose (1-40 mmol/L) or angiotensin II (Ang II, $10^{-8}-10^{-5}$ $\mathrm{mol} / \mathrm{L}$ ) for $24 \mathrm{~h}$, and the expression of fibronectin, collagen3A1, collagen-4A1, phospho-ERK1/2, ERK1/2 and phosphonuclear factor-kappa B (NF-kB) was measured by Western blotting. Based on preliminary dose-response data, in which glucose and Ang II were found to be most effective to fibrotic signals at $20 \mathrm{mmol} / \mathrm{L}$ and $10^{-7} \mathrm{~mol} / \mathrm{L}$, separately, we used these concentrations to study time-response of fibrotic and ERK/NF-KB signals in cardiac fibroblasts. In the subsequent experiments, cardiac fibroblasts were pretreated with $0.3,3$ and $30 \mathrm{nmol} / \mathrm{L}$ linagliptin or 10, 50 and $100 \mathrm{nmol} / \mathrm{L}$ liraglutide for $1 \mathrm{~h}$, and then exposed to glucose $(20 \mathrm{mmol} / \mathrm{L})$ or Ang II $\left(10^{-7} \mathrm{~mol} / \mathrm{L}\right)$ for $24 \mathrm{~h}$, and the expression of fibrotic and ERK/ NF-KB signals was assessed again by Western blotting.

In the preliminary study, we found that low concentrations of glucose and Ang II have no effect on F-actin degradation. So, we exposed cardiac fibroblasts to glucose $(1-160 \mathrm{mmol} / \mathrm{L})$ or Ang II $\left(10^{-8}-10^{-5} \mathrm{~mol} / \mathrm{L}\right)$ for $24 \mathrm{~h}$ to assess the effect of glucose and Ang II on F-actin degradation. We found that only $\geq 40 \mathrm{mmol} / \mathrm{L}$ glucose and $\geq 10^{-6} \mathrm{~mol} / \mathrm{L}$ Ang II could cause F-actin degradation. In subsequent experiments, cardiac fibroblasts pretreated with $30 \mathrm{nmol} / \mathrm{L}$ linagliptin or $100 \mathrm{nmol} / \mathrm{L}$ liraglutide for $1 \mathrm{~h}$, and then exposed to $40 \mathrm{mmol} / \mathrm{L}$ glucose or $10^{-6} \mathrm{~mol} / \mathrm{L}$ Ang II for $24 \mathrm{~h}$ to study the effect linagliptin and liraglutide on glucose- or Ang II-induced F-actin degradation.

\section{Western blotting assay}

Proteins were extracted using cell lysis buffer supplemented with protease inhibitor cocktail and phosphatase inhibitor cocktail, and protein concentrations were measured by Bradford assay. Proteins $(20 \mu \mathrm{g} / \mathrm{sample}$ diluted in Laemmli sample Buffer) were loaded into 12\% precast SDS-PAGE gels and separated by electrophoresis. Following electrophoresis, the proteins were transferred onto $0.45 \mu \mathrm{m}$ nitrocellulose blotting membranes. The blots were blocked by $5 \%$ non-fat milk in Tris buffered saline with Tween-20 (TBS-T) for $1 \mathrm{~h}$ at room temperature, and then incubated with primary antibodies (1:1000-1:2000) in blocking solution at $4{ }^{\circ} \mathrm{C}$ overnight. After washing with TBS-T for 3 times, the blots were incubated with HRP-conjugated secondary antibodies (1:10 000) in blocking solution for $1 \mathrm{~h}$ at room temperature. The immunoreactive bands were visualized by incubation with Western Blotting Luminol Reagents for $3 \mathrm{~min}$ and then exposed to blue basic autorad film. The protein bands were scanned and quantified by Image J software.

\section{Cytoskeleton assay}

Cardiac fibroblasts were stained with Rhodamine phalloidin (Invitrogen, Grand Island, NY, USA), and F-actin distribution in cardiac fibroblasts was assayed using an inverted laser confocal microscope. The detailed protocol has been recently published ${ }^{[11]}$. 


\section{Statistical analysis}

Statistical analysis was performed with SPSS11.5 software. Data are presented as means and standard deviation (SD) from 4-5 independent experiments. Univariate comparisons of means were evaluated using one-way ANOVA with Tukey's post-hoc adjustment for multiple comparisons. $P$ value $<0.05$ was considered statistically significant.

\section{Results}

Modulation of fibrosis signals in response to glucose and angiotensin II

Previous studies have demonstrated that high concentrations of glucose promote cardiac secretion of collagens by fibroblasts $^{[12]}$. In this study, we found that the expression of fibro- nectin, collagen-3A and collagen-4A was markedly increased in cardiac fibroblasts in response to glucose or Ang II. This effect was dependent on the concentration of glucose (1-40 $\mathrm{mmol} / \mathrm{L})$ or Ang II $\left(10^{-8}-10^{-5} \mathrm{~mol} / \mathrm{L}\right)$ (Figure $1 \mathrm{~A}$ and $\left.1 \mathrm{~B}\right)$ as well as duration of incubation (Figure 1C and 1D). The concentration of glucose that consistently increased the expression of fibronectin and collagens was $20 \mathrm{mmol} / \mathrm{L}$; and the concentration of Ang II that consistently increased the expression of fibronectin and collagens was $10^{-7} \mathrm{~mol} / \mathrm{L}$ (Figure $1 \mathrm{~A}$ and $1 \mathrm{~B}$ ). The duration of incubation that consistently increased the expression of collagens was $24 \mathrm{~h}$ (Figure 1C and 1D). These concentrations and incubation time were used in subsequent experiments.

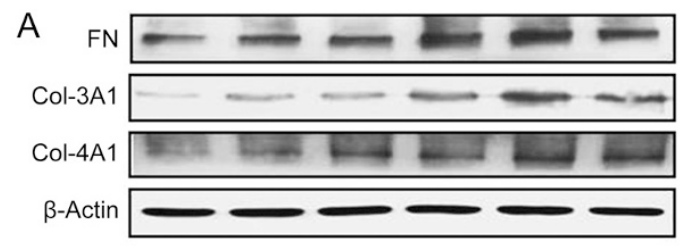

B
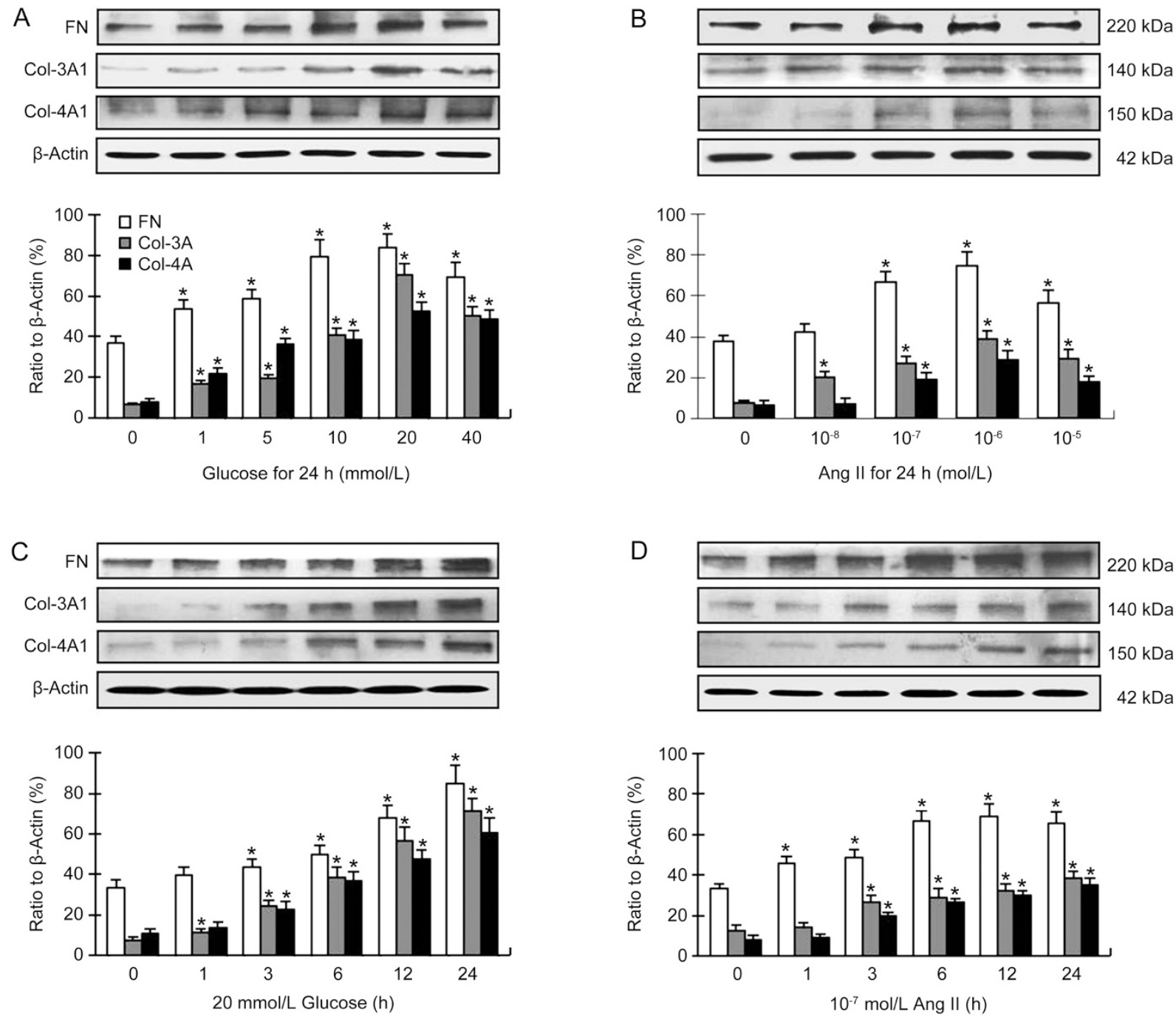

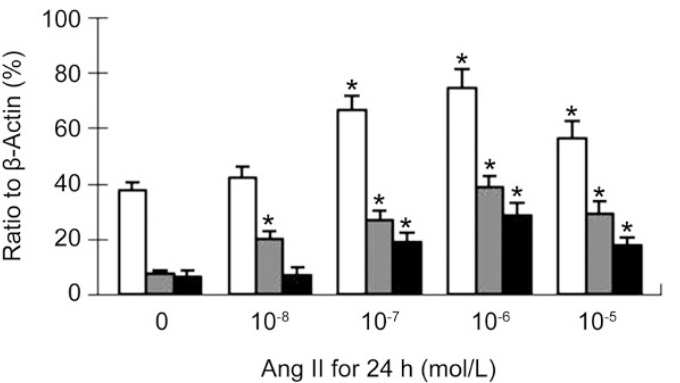

D
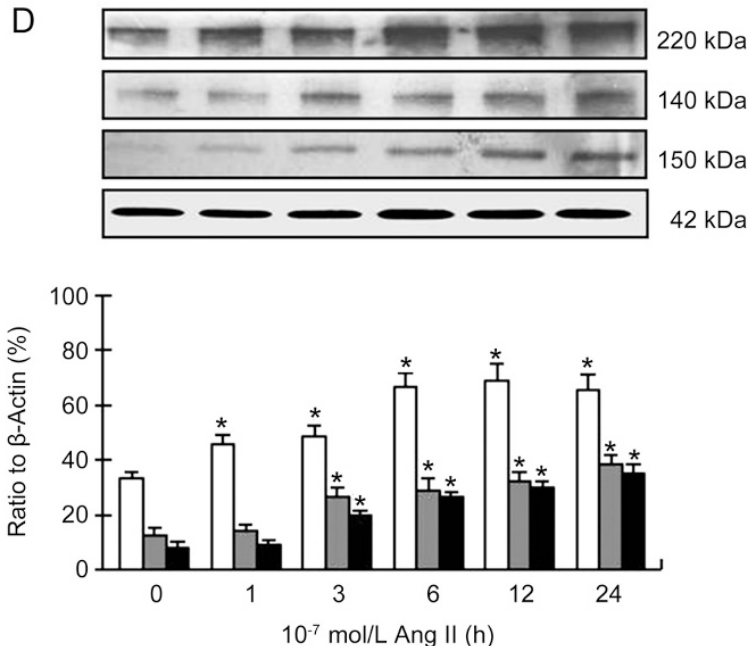

Figure 1. (A, B) Dose responses of fibronectin (FN), collagen-3 (Col-3A1) and collagen-4 (Col-4A1) formation in mouse cardiac fibroblasts to different concentrations of glucose (Glu) and angiotensin II (Ang II), and incubation time is $24 \mathrm{~h}$. The concentration of glucose that consistently increased the expression of fibronectin and collagens was $20 \mathrm{mmol} / \mathrm{L}$, and the concentration of angiotensin II that consistently increased the expression of fibronectin and collagens was $10^{-7}$ or $10^{-6} \mathrm{~mol} / \mathrm{L}$. (C, D) Time responses of fibronectin and collagens to $20 \mathrm{mmol} / \mathrm{L}$ glucose and $10^{-7}$ mol/L angiotensin II. The duration of incubation that consistently increased the expression of fibronectin and collagens was $24 \mathrm{~h}$. Mean \pm SD. Bar graphs represent 4-5 independent experiments. ${ }^{*} P<0.05$ vs control. 

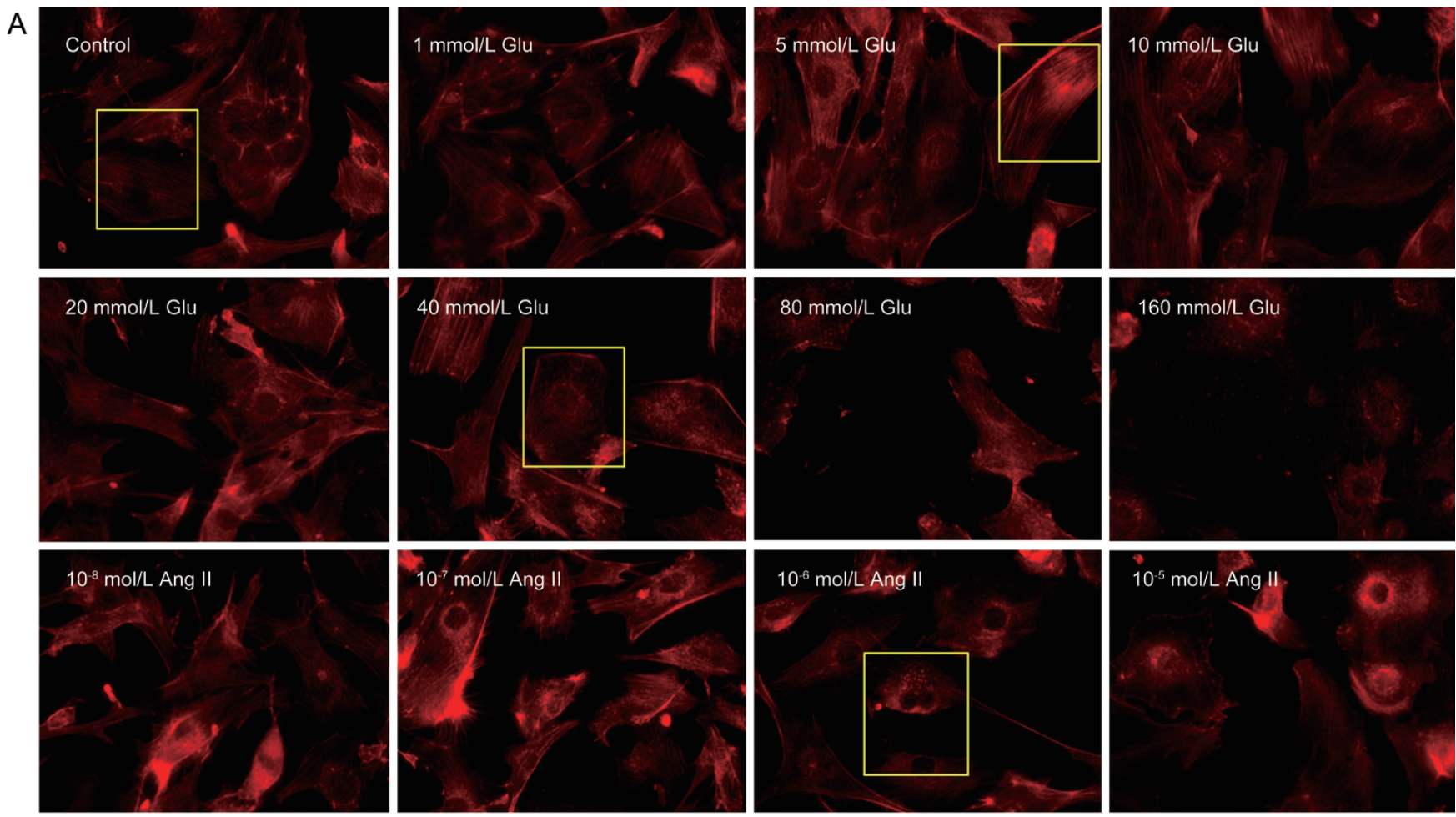

B
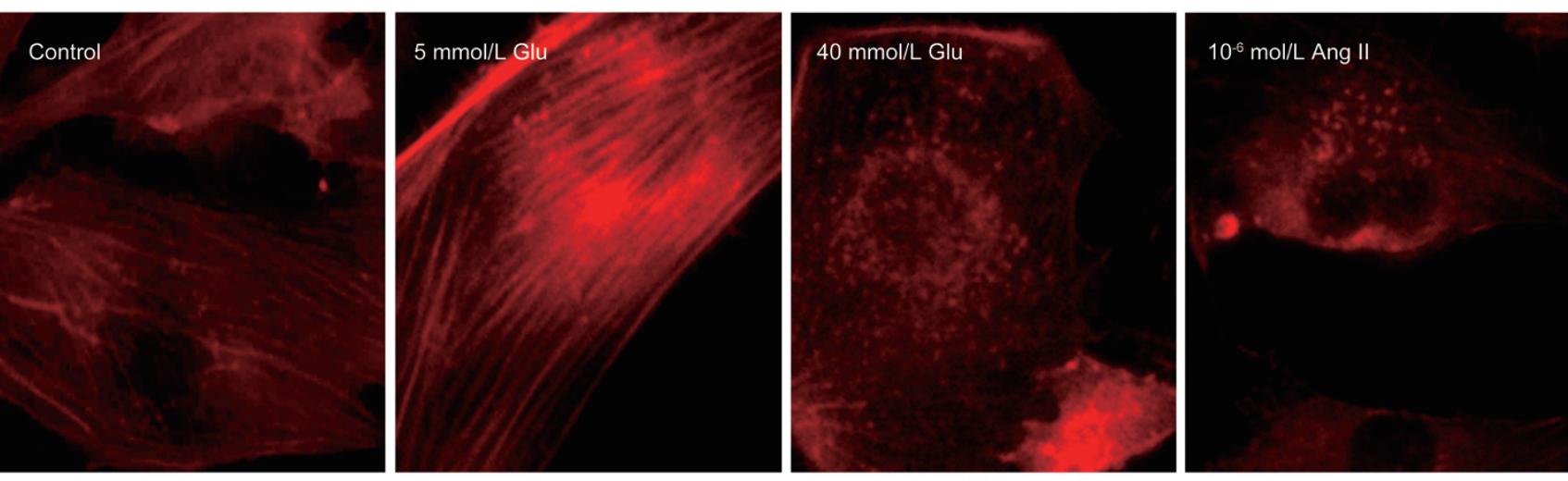

C
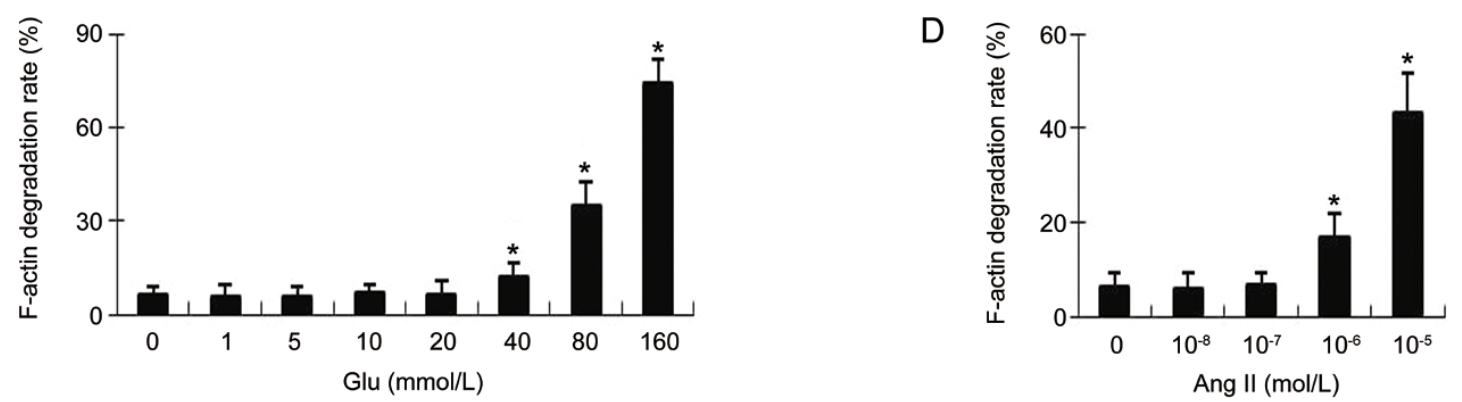

Figure 2. Degradation of F-actin following exposure of cardiac fibroblasts to different concentrations of glucose (Glu) and angiotensin II (Ang II). (A) Rhodamine phalloidin staining shows F-actin morphology and degradation in cardiac fibroblasts following exposure to 1-160 mmol/L glucose and $10^{-8}$ $10^{-5} \mathrm{~mol} / \mathrm{L}$ angiotensin II for $24 \mathrm{~h}(400 \times)$. Glucose $(\geq 40 \mathrm{mmol} / \mathrm{L})$ and angiotensin $\left(\geq 10^{-6} \mathrm{~mol} / \mathrm{L}\right)$ each induced degradation of F-actin in cardiac fibroblasts; however, glucose $(\leq 20 \mathrm{mmol} / \mathrm{L})$ and angiotensin II $\left(\leq 10^{-7} \mathrm{~mol} / \mathrm{L}\right)$ did not significantly affect F-actin degradation. The degradation of F-actin was defined as the cells with less actin filaments. (B) Amplified single cell images show that high concentrations of glucose $(40 \mathrm{mmol} / \mathrm{L})$ and angiotensin II $\left(10^{-6} \mathrm{~mol} / \mathrm{L}\right)$ cause F-actin degradation. The assembly F-actin filaments are clearly shown in control fibroblasts and fibroblasts treated with $5 \mathrm{mmol} / \mathrm{L}$ glucose, but much less in the cells treated with $40 \mathrm{mmol} / \mathrm{L}$ glucose and $10^{-6} \mathrm{~mol} / \mathrm{L}$ angiotensin II. (C) The bar graph shows the quantification of F-actin degradation rates (the cells with degraded F-actin vs total cells) following exposure of fibroblasts to different concentrations of glucose. (D) The bar graph shows the quantification of F-actin degradation rate following exposure of fibroblasts to different concentrations of angiotensin II. Each figure represents cells in 20 randomly selected microscopic fields (five fields/sample). Mean \pm SD. Bar graphs represent summary of 5 independent experiments. ${ }^{*} P<0.05$ vs control. 
F-actin degradation in response to glucose and Ang II

Next, we checked the effect of glucose and Ang II on F-actin organization in cardiac fibroblasts. As shown in Figure 2, glucose $(\geq 40 \mathrm{mmol} / \mathrm{L})$ and Ang II $\left(\geq 10^{-6} \mathrm{~mol} / \mathrm{L}\right)$ each induced degradation of F-actin (less assembly F-actin fibers and/or more disassembly fibers) in cardiac fibroblasts. Of note, low concentrations of glucose $(\leq 20 \mathrm{mmol} / \mathrm{L})$ and Ang II $\left(\leq 10^{-7}\right.$ mol/L) did not significantly affect the integrity of F-actin fibers.

\section{ERK1/2 and NF-KB in response to glucose and Ang II}

Huang et al showed that glucose increased the phosphorylation of ERK1/2, JNK and NF-KB-p65 in rat mesangial cells ${ }^{[13]}$. Glucose $(25 \mathrm{mmol} / \mathrm{L})$ has also been shown to stimulate the phosphorylation of ERK1/2 in cardiac fibroblasts ${ }^{[12]}$. There were rare reports about the effect of glucose on the phosphorylation of NF-kB in cardiac fibroblasts. However, several studies indicated that glucose $(25 \mathrm{mmol} / \mathrm{L})$ could promote the phosphorylation of NF-kB-p65 in other lineages of fibroblasts such as $3 \mathrm{~T} 3$ cells $^{[14]}$. In the present study, we found that glucose (1-40 mmol/L) increased the expression of phosphoERK1/2 and phospho-NF-kB-p65 in cardiac fibroblasts (Figure $3 \mathrm{~A})$. The concentration of glucose that consistently stimulated the expression of phospho-ERK1/2 (vs ERK1/2) and phosphoNF-кB-p65 was $5 \mathrm{mmol} / \mathrm{L}$ (Figure 3A). The expression of phospho-ERK1/2 and phospho-NF-kB-p65 was also markedly increased in a time-response manner as the cells were exposed to $20 \mathrm{mmol} / \mathrm{L}$ glucose (Figure $3 \mathrm{~B}$ ). Of note, glucose did not affect the level of unphosphorylated ERK1/2.

Ang II is another activator of ERK1/2-NF-KB pathway. Previous studies have shown that treatment with Ang II can activate ERK1/2 and NF- $\mathrm{KB}$ in cardiac fibroblasts ${ }^{[11,15]}$. In accordance with these studies, we observed that phospho-ERK1/2 and phospho-NF-kB-p65 were markedly upregulated in car-
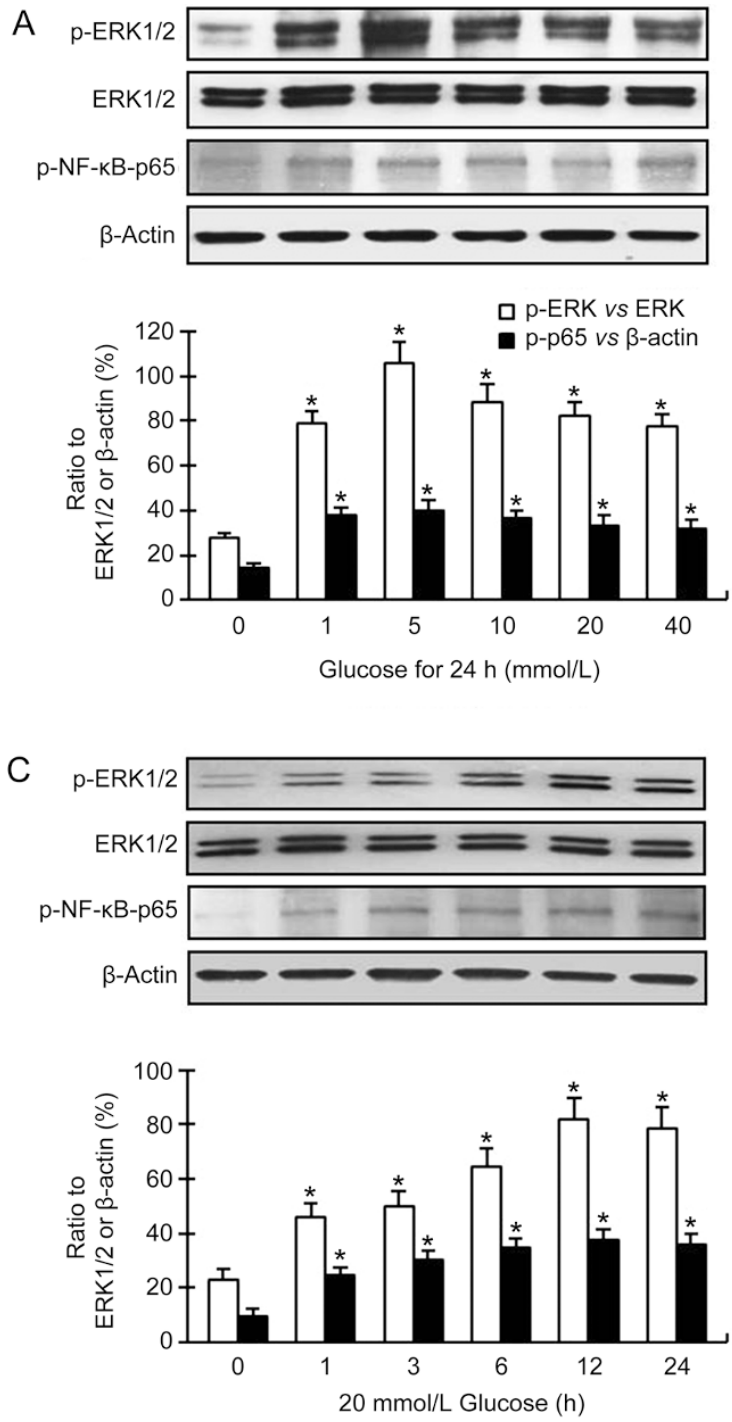

B
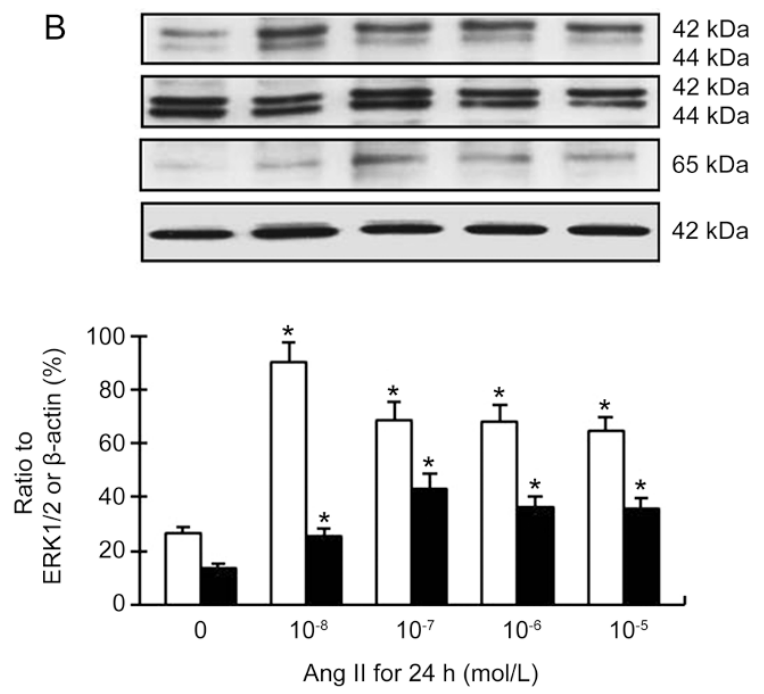

D
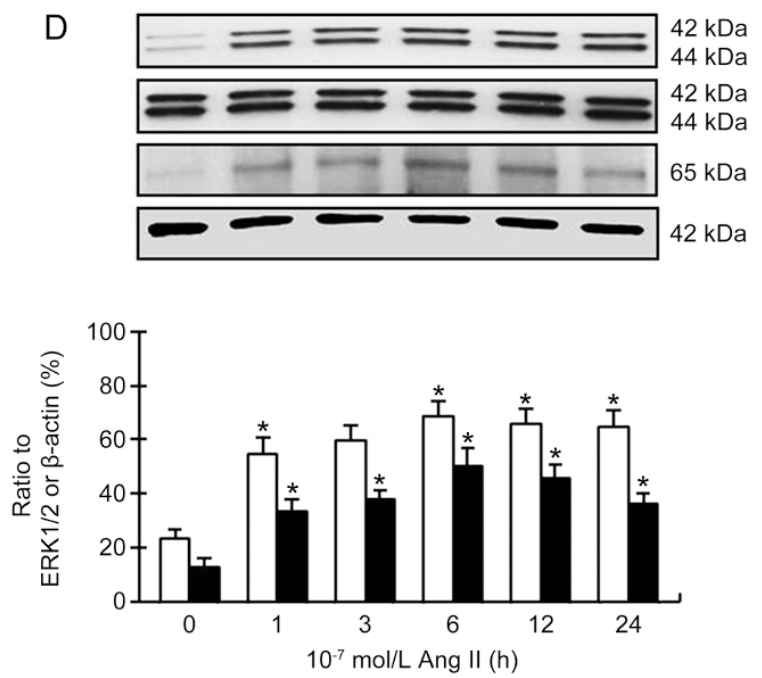

Figure 3. (A, B) Dose responses of phospho-ERK1/2 and phospho-NF-KB-p65 in cardiac fibroblasts to different concentrations of glucose (Glu) and angiotensin II (Ang II), incubation time $24 \mathrm{~h}$; (C, D) Time responses of phospho-ERK1/2 and phospho-NF-kB-p65 to $20 \mathrm{mmol} / \mathrm{L}$ glucose and $10^{-7} \mathrm{~mol} / \mathrm{L} \mathrm{Ang} \mathrm{II,}$ incubation time 1-24 h. Mean \pm SD. Bar graphs represent data from 4-5 independent experiments. ${ }^{*} P<0.05$ vs control. 
diac fibroblasts following exposure to Ang II $\left(10^{-8}-10^{-5} \mathrm{~mol} / \mathrm{L}\right)$ (Figure 3). The concentration of Ang II that consistently stimulated the expression of phospho-ERK1/2 and phosphoNF-kB-p65 was $10^{-7} \mathrm{~mol} / \mathrm{L}$ (Figure 3C). The expression of phospho-ERK1/2 and phospho-NF-kB-p65 was increased in a time-response manner (Figure 3D). Of note, exposure to $10^{-7}$ $\mathrm{mol} / \mathrm{L}$ Ang II for 6-24 h consistently increased the expression of phospho-ERK1/2 (Figure 3D). Ang II did also not affect the level of unphosphorylated ERK1/2 $(P>0.05)$.

\section{Modulation of the expression of fibronectin and collagens by linagliptin and liraglutide}

As shown in Figure 4A, both liraglutide and linagliptin in all concentrations modestly, but significantly, reduced glucoseinduced fibronectin expression in cardiac fibroblasts $(P<0.05)$. Liraglutide (in all concentrations, $10-100 \mathrm{nmol} / \mathrm{L}$ ) significantly reduced glucose-induced collagen- 1 and -3 expression $(P<0.05$ or $P<0.01)$. Liraglutide at high concentrations (50 and $100 \mathrm{nmol} / \mathrm{L}$ ) also significantly reduced glucose-induced collagen-4 expression $(P<0.01)$, but at low concentration $(10$ $\mathrm{nmol} / \mathrm{L}$ ) did not significantly affect glucose-induced collagen-4 expression $(P>0.05)$. Linagliptin (in all concentrations, 0.3-30 nmol/L) significantly reduced glucose-induced collagen-3 and -4 expression $(P<0.05$ or $P<0.01)$. Linagliptin at high concentrations ( 3 and $30 \mathrm{nmol} / \mathrm{L}$ ), but not at low concentration $(0.3 \mathrm{nmol} / \mathrm{L})$, also significantly reduced glucose-induced collagen-1 expression $(P<0.05$ or $P<0.01)$.

Next, we checked the effects of liraglutide and linagliptin on Ang II-induced fibronectin and collagen expression. As shown in Figure 4B, liraglutide (in all concentrations) and linagliptin (3 and $30 \mathrm{nmol} / \mathrm{L}$ ) significantly reduced Ang II-
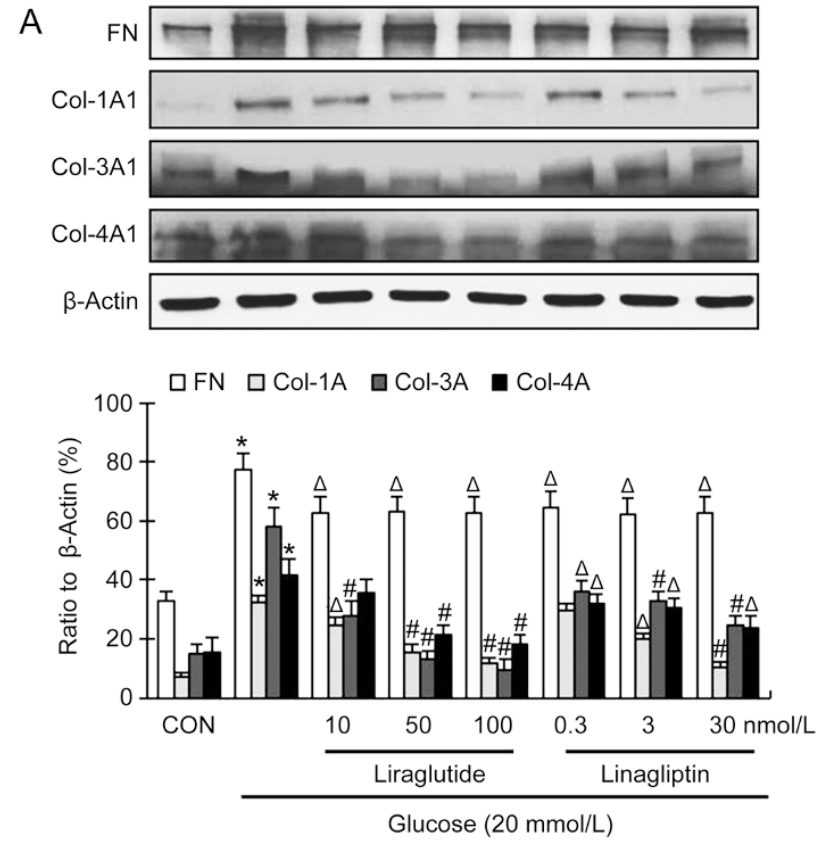

induced fibronectin expression $(P<0.05$ or $P<0.01)$. Linagliptin at low concentration $(0.3 \mathrm{nmol} / \mathrm{L})$ also modestly, but not significantly, reduced Ang II-induced fibronectin expression $(P>0.05)$. Both linagliptin and liraglutide in all concentrations significantly reduced Ang II-induced collagen-1 expression $(P<0.05$ or $P<0.01)$. Linagliptin in all concentrations also significantly reduced Ang II-induced collagen- 3 and -4 expression $(P<0.05$ or $P<0.01)$. Liraglutide at high concentrations ( 50 and $100 \mathrm{nmol} / \mathrm{L})$, but not at low concentration $(10 \mathrm{nmol} / \mathrm{L})$, also significantly reduced the Ang II-induced collagen-3 and -4 expression $(P<0.01)$.

\section{Modulation of F-actin degradation by linagliptin and liraglutide} As shown in Figure 5, liraglutide (100 nmol/L) and linagliptin $(30 \mathrm{nmol} / \mathrm{L})$ both markedly inhibited glucose-induced F-actin degradation $(P<0.05$ or $P<0.01)$. Liraglutide also significantly inhibited Ang II-induced F-actin degradation $(P<0.05)$; linagliptin, on the other hand, did not show this effect $(P>0.05)$.

\section{Modulation of activation of ERK1/2 and NF-KB by linagliptin and liraglutide}

The activation of ERK1/2-NF-kB pathway contributes to cytoskeleton organization in many types of cells and collagen formation in fibroblasts ${ }^{[16,17]}$. As shown in Figure 6A, both liraglutide and linagliptin in all concentrations significantly decreased glucose-induced phospho-ERK1/2 and phosphoNF-KB expression in a dose-dependent manner $(P<0.05$ or $P<0.01)$.

Liraglutide in all concentrations significantly reduced Ang II-induced phospho-ERK1/2 and phospho-NF-kB expression (Figure 6B; $P<0.05$ or $P<0.01$ ). Linagliptin in all concentrations
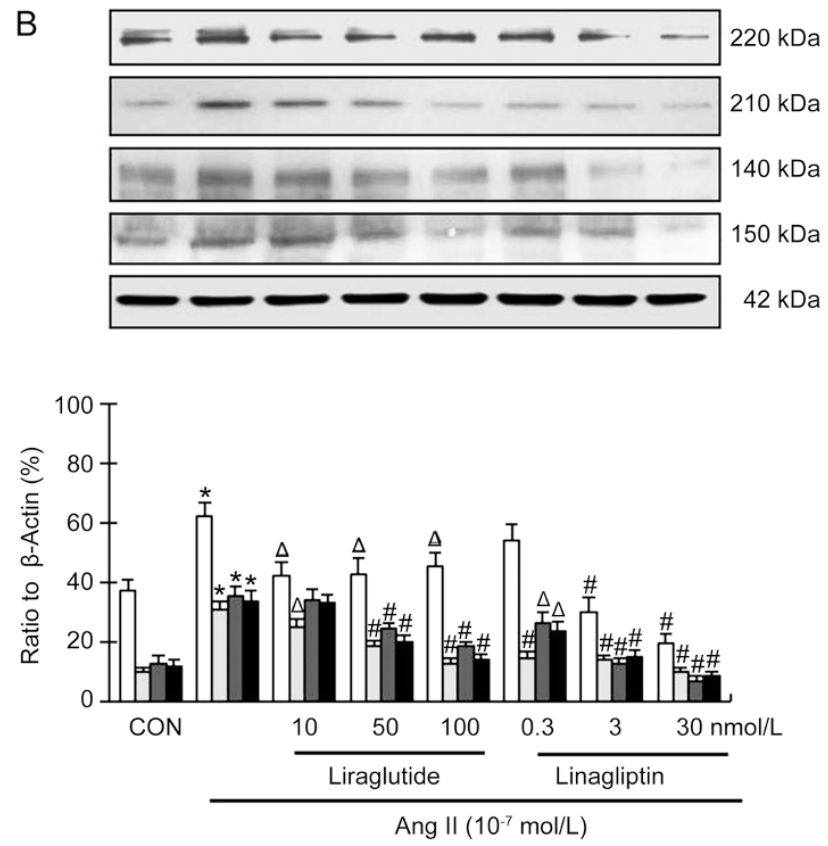

Figure 4. Modulatory effects of linagliptin and liraglutide on glucose $(20 \mathrm{mmol} / \mathrm{L})$ - and angiotensin II (10 $\left.{ }^{-7} \mathrm{~mol} / \mathrm{L}\right)$-induced fibronectin (FN), collagen-3 (Col-3A1) and collagen-4 (Col-4A1) formation in cardiac fibroblasts. Bar graphs represent data from 4 independent experiments. ${ }^{*} P<0.01$ vs control; ${ }^{\triangle} P<0.05,{ }^{\#} P<0.01$ vs glucose or angiotensin II alone. 

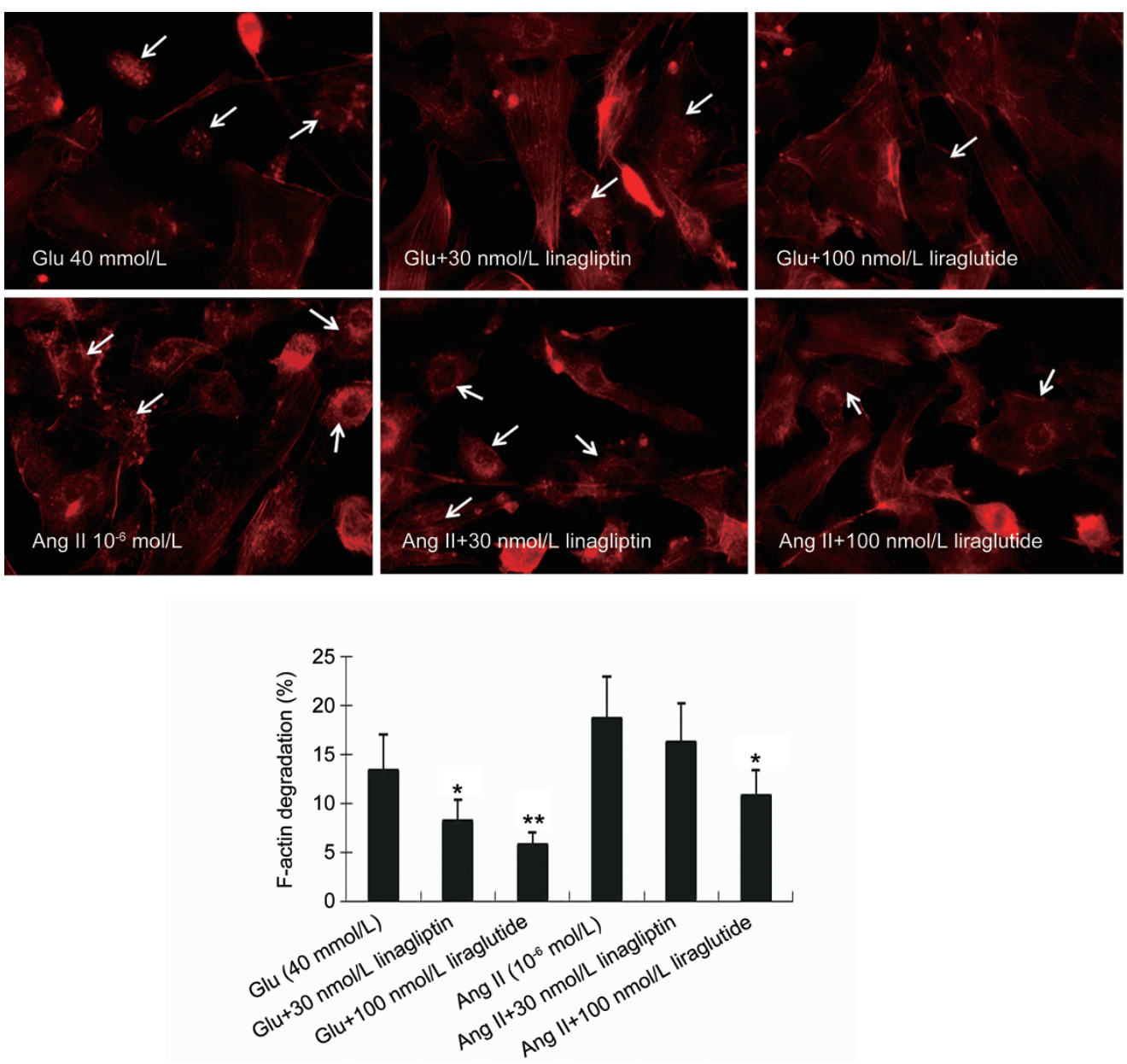

Figure 5. Modulatory effects of linagliptin and liraglutide on glucose (40 mmol/L)- and angiotensin II (10 $0^{-6}$ mol/L)-induced F-actin degradation in cardiac fibroblasts. Linagliptin $(30 \mathrm{nmol} / \mathrm{L})$ and liraglutide $(100 \mathrm{nmol} / \mathrm{L})$ both protect actin filament from disassembly caused by treatment with glucose. Liraglutide also significantly inhibits angiotensin II-induced actin filament disassembly in cardiac fibroblasts, but linagliptin does not show this effect. Each figure represents cells in 20 randomly selected microscopic fields (five fields/sample). Mean \pm SD. Bar graphs represent summary of 5 independent experiments. ${ }^{*} P<0.05,{ }^{* *} P<0.01$ vs glucose- or angiotensin II-alone.

also significantly reduced Ang II-induced phospho-ERK1/2 expression in a dose-dependent manner $(P<0.05$ or $P<0.01)$. However, linagliptin only at high concentrations $(3$ and 30 nmol/L) significantly reduced Ang II-induced phospho-NF-кB expression.

Of note, ERK1/2 inhibitor U0126 (10 $\mu \mathrm{mol} / \mathrm{L})$ and NF-KB inhibitor JSH-23 $(10 \mu \mathrm{mol} / \mathrm{L})$ both markedly suppressed glucose- and angiotensin II-induced fibronectin and collagen expressions in cardiac fibroblasts (Figure 7; $P<0.05$ or $P<0.01$ ). This indicates that the activity of ERK-NF- $\mathrm{kB}$ pathway may be correlated with the effects of linagliptin and liraglutide on collagen synthesis by cardiac fibroblasts in response to glucose and Ang II.

\section{Discussion}

The precise mechanisms underlying DPP-4 inhibitorsmediated inhibition of cardiac remodeling in diabetes when blood sugar levels are high remain largely undefined. Similarly, the mechanisms of cardiac fibrosis in myocardial ischemia, hypertension and aging when Ang II activity is increased remain unknown.

The present study was designed to study the modulation of glucose- and Ang II-induced collagen formation and actin cytoskeletal disassembly by DPP-4 inhibitor linagliptin and GLP-1 activator liraglutide. We found that both linagliptin and liraglutide inhibited the expression of fibronectin, collagen- 1 , collagen- 3 and collagen- 4 in the cultured mouse cardiac fibroblasts treated with glucose or Ang II. Liraglutide and linagliptin both partially, but significantly, inhibited F-actin fiber degradation induced by glucose (both linagliptin and liraglutide) or Ang II (only liraglutide). Lastly, we observed that linagliptin and liraglutide inhibited glucoseand Ang II-stimulated activation of ERK1/2 and NF-KB. These intracellular signals might be the mechanism by which linagliptin and liraglutide modulate cardiac fibroblast biology in vivo in pathological states.

Glucose is an important stimulus for collagen formation in the heart under diabetic environment. In vitro studies have 
A
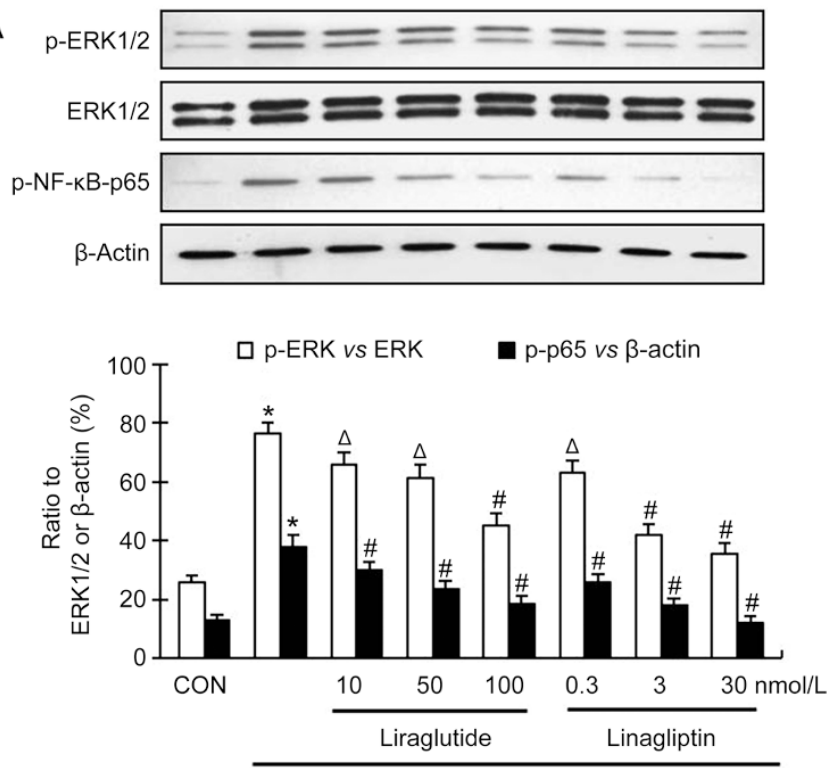

Glucose $(20 \mathrm{mmol} / \mathrm{L})$
B
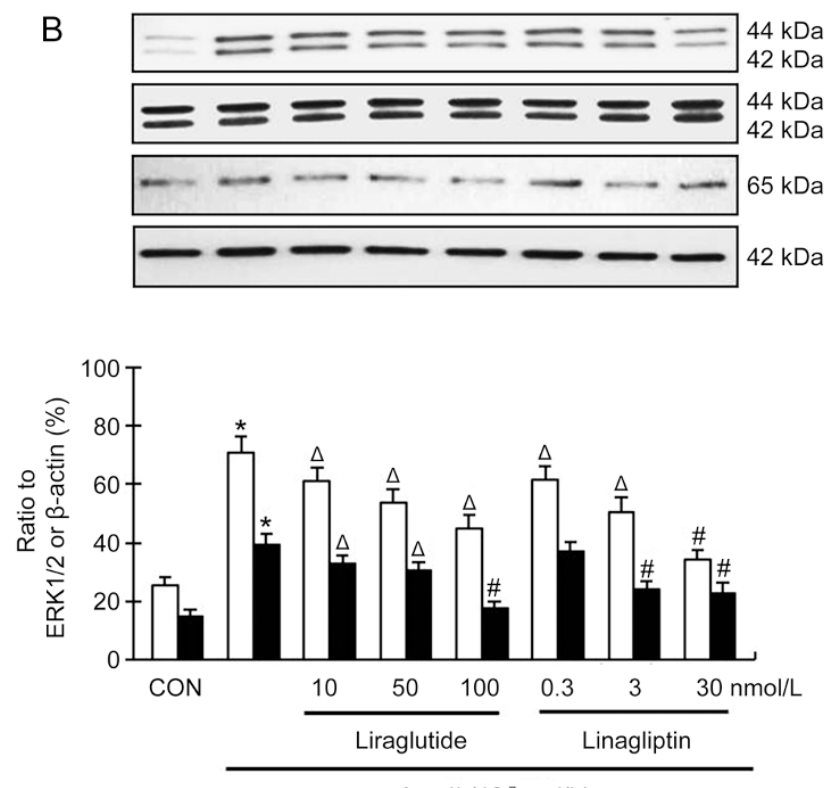

Ang II $\left(10^{-7} \mathrm{~mol} / \mathrm{L}\right)$

Figure 6. Modulatory effect of linagliptin and liraglutide on glucose $(20 \mathrm{mmol} / \mathrm{L})$ - and angiotensin II (10 $\left.{ }^{-7} \mathrm{~mol} / \mathrm{L}\right)$-changes of phospho-ERK1/2 and phospho-NF-kB-p65 in cardiac fibroblasts. Both liraglutide and linagliptinin in all concentrations significantly inhibits glucose-induced expression of phosphoERK1/2 and phospho-NF-KB-p65 in cardiac fibroblasts. Liraglutide in all concentrations also significantly inhibits angiotensin II-induced expression of phosphoERK1/2 and phospho-NF-KB-p65. Linagliptin except dose at $0.3 \mathrm{nmol} / \mathrm{L}$ also inhibits angiotensin II-induced expression of phospho-ERK1/2 and phospho-NFKB-p65. Mean \pm SD. Bar graphs represent data from 4 independent experiments. ${ }^{*} P<0.01$ vs control. ${ }^{A} P<0.05,{ }^{\#} P<0.01$ vs glucose or angiotensin II alone.

demonstrated that hyperglycemia promotes collagen synthesis by cardiac fibroblasts through the activation of ERK1/2 pathway ${ }^{[12]}$. Another study has shown that hyperglycemia and Ang II synergistically enhance collagen synthesis by cardiac fibroblasts through the activation of ROS-STAT3 pathway ${ }^{[18]}$. Ang II, the major mediator of the renin-angiotensin-system contributes to a range of cardiovascular pathologies. In cardiovascular system, the canonical effects of Ang II are mediated primarily by expression and activation of its type 1 (AT1R) and type 2 (AT2R) receptors. In a previous study, we showed that Ang II stimulated collagen production as well as MMP expression in cardiac fibroblasts through activation of $\mathrm{AT} \mathrm{R}^{[10]}$. In accordance with previous work, we observed again that the expression of fibronectin, collagen-1A1, collagen-3A1 and collagen-4A1 was markedly increased in cardiac fibroblasts following exposure to Ang II for $24 \mathrm{~h}$. Exposure of fibroblasts to glucose had qualitatively similar effect. These effects of glucose or Ang II were largely concentration-dependent.

More importantly, both linagliptin and liraglutide decreased glucose- and Ang II- induced fibronectin and collagen accumulation in cardiac fibroblasts. Although these effects of linagliptin and liraglutide were observed in relatively high concentrations, the plasma concentrations of linagliptin and liraglutide in the diabetic heart are unknown. Cmax of linagliptin in human is $9 \mathrm{nmol} / \mathrm{L}$, and that of liraglutide is 9.4 $\mathrm{nmol} / \mathrm{L}$ following a subcutaneous single dose of liraglutide $(0.6 \mathrm{mg})$. It is possible that prolonged use of linagliptin and liraglutide leads to tissue concentrations used in the present in vitro study.
The integrity of cytoskeleton is an important factor to maintain the function of cardiac fibroblasts ${ }^{[19]}$. The disassembly of F-actin cytoskeleton inhibits migration of cardiac fibroblasts ${ }^{[20]}$, and the inhibition of F-actin assembly has also been proved to inhibit the fibroblast-myofibroblast transition ${ }^{[21]}$. An in vivo study has also shown that actin cytoskeleton remodeling attenuates myocardial fibrosis following myocardial infarction in rats ${ }^{[22]}$. A series of studies have demonstrated that high level of ROS can impair the integrity and function of cytoskeleton in a variety of cells including fibroblasts, and reduction of ROS production via antioxidant therapy can stabilize cytoskeleton by targeting the ROCK1 pathway ${ }^{[23,24]}$. While it is known that glucose and Ang II are strong stimuli for ROS production, the effects of glucose and Ang II on cytoskeleton organization in cardiac fibroblasts have not been previously studied. In this study, we demonstrated that both glucose and Ang II affected F-actin integrity in cardiac fibroblasts albeit in high concentrations ( $\geq 40 \mathrm{mmol} / \mathrm{L}$ and $\geq 10^{-6} \mathrm{~mol} / \mathrm{L}$, respectively). Linagliptin and liraglutide each partially inhibited glucose-induced degradation of F-actin fibers. The effect of linagliptin and liraglutide on glucose-induced F-actin disassembly probably involves their ROS inhibitory actions. Previous studies have adequately demonstrated that both these drugs suppress highglucose-induced ROS production in various types of cells ${ }^{[25,26]}$. Of note, the Ang II-induced F-actin degradation was attenuated by liraglutide, but not by linagliptin. This suggests that direct augmentation of GLP-1 by liraglutide may be somewhat superior to the indirect augmentation by linagliptin. However, this remains unknown. 

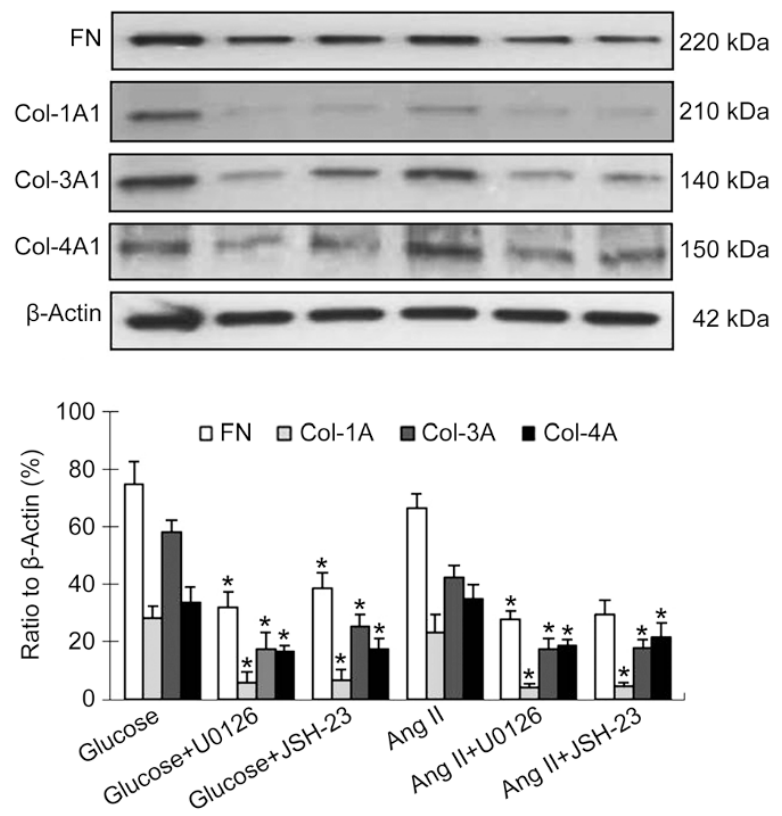

Figure 7. Effect of ERK1/2 and NF-KB inhibitors on collagen formation in cardiac fibroblasts in response to glucose and angiotensin II (Ang II). ERK1/2 inhibitor U0126 (10 $\mu \mathrm{mol} / \mathrm{L})$ and NF-KB inhibitor JSH-23 (10 $\mu \mathrm{mol} / \mathrm{L})$ both markedly inhibited glucose $(20 \mathrm{mmol} / \mathrm{L})$ - and Ang $\mathrm{II}\left(10^{-7}\right.$ mol/L)-induced fibronectin (FN), collagen-3 (Col-3A1) and collagen-4 (Col$4 A 1)$ expression in cardiac fibroblasts. Mean \pm SD. Bar graphs represent data from 4 independent experiments. ${ }^{*} P<0.05$ vs glucose- or Ang IIgroup.

ERK1/2 are important members of the mitogen-activated protein kinase super family that widely regulate cell function nearly in all cell types, particularly cell proliferation. The activation of NF-KB, which is downstream of mitogen-activated protein kinases, has also been shown to participate in several physiological processes in cardiac fibroblasts ${ }^{[27]}$. The activation of ERK1/2 and NF-KB has been shown to be involved in collagen deposition in the hearts of diabetic and hypertensive animals ${ }^{[28-31]}$. Ang II and glucose-induced collagen accumulation in the cultured cardiac fibroblasts has also been demonstrated to involve the activation of ERK1/2 and NF- $\mathrm{KB}^{[10,12,32]}$. High concentrations of glucose and Ang II can indeed activate ERK1/2 and/or NF-KB in other types of cells ${ }^{[13]}$. These previous data were confirmed in the present study in mouse cardiac fibroblasts. Interestingly, linagliptin and liraglutide both inhibited glucose- and Ang II-induced activation of ERK1/2 and NF-KB-p65. We suggest that the reduction of fibronectin and collagens in cardiac fibroblasts by linagliptin and liraglutide may be mediated, at least to a large extent, via inhibition on ERK1/2 and NF-KB-p65. It is known that the increase of intracellular ROS would cause the activation of ERK1/2 and NF-kB signals ${ }^{[10,25,33]}$. The inhibitory effects of linagliptin and liraglutide on ERK1/2-NF-KB pathway may depend on their roles in reduction of ROS production in cardiac fibroblasts. The effect of linagliptin and liraglutide on cytoskeleton may only be partially related to inhibition of ERK1/2 and
NF-kB-p65 activation, since these agents both markedly inhibited the activation of ERK1/2 and NF- $\mathrm{KB}$ as well as F-actin degradation in response to glucose $(40 \mathrm{mmol} / \mathrm{L})$, and both agents at high concentrations also markedly inhibited Ang IIinduced the activation of ERK1/2 and NF-KB, but only liraglutide inhibited Ang II-induced F-actin degradation, linagliptin did not show this effect. Thus it is likely that signals besides ERK1/2 and NF-kB-p65 are also involved in the overall effects of linagliptin and liraglutide on fibroblast biology in response to glucose and Ang II.

\section{Conclusion}

The DPP-4 inhibitor linagliptin and the GLP-1 activator liraglutide both inhibited glucose- and Ang II-induced expression of fibrotic signals in mouse cardiac fibroblasts, which may be related to the activation of ERK1/2 and NF-KB-p65. Liraglutide and linagliptin also inhibited glucose- as well as Ang IIinduced F-actin degradation in cardiac fibroblasts, albeit in large concentrations. These observations suggest that ERK1/2 and NF-kB-p65 activation are a basis of the effect of DPP-4 inhibitors and GLP-1 activators in cardiac remodeling in diabetic and non-diabetic states. However, there may be involvement of other pathways besides ERK1/2 and NF-KB-p65 activation in the overall cardiac remodeling modulatory effects of these agents.

\section{Acknowledgements}

This study was supported by grants from the Department of Veterans Affairs, Veterans Health Administration, Office of Research and Development, Biomedical Laboratory Research and Development (Washington, DC, USA) (grant № BX-000282-05), the National Natural Science Foundation of China (grant № 81370428 and 31401246) and Boehringer Ingelheim Pharmaceuticals, Inc (Ridgefield, CT, USA).

\section{Author contribution}

Xian-wei WANG and Jawahar L MEHTA designed the experiments; Xian-wei WANG, Fen-xi ZHANG, Fen YANG, Zu-feng DING, and Nidhi AGARWAL performed the experiments and analyzed the data; Xian-wei WANG and Jawahar L MEHTA wrote the manuscript; Zhi-kun GUO gave the study suggestion and revised the manuscript.

\section{References}

1 Lee TI, Kao YH, Chen YC, Huang JH, Hsu MI, Chen YJ. The dipeptidyl peptidase-4 inhibitor-sitagliptin modulates calcium dysregulation, inflammation, and PPARs in hypertensive cardiomyocytes. Int J Cardiol 2013; 168: 5390-5.

2 Zhao Y, Yang L, Zhou Z. Dipeptidyl peptidase-4 inhibitors: multitarget drugs, not only antidiabetes drugs. J Diabetes 2014; 6: 21-9.

3 Lenski M, Kazakov A, Marx N, Böhm M, Laufs U. Effects of DPP-4 inhibition on cardiac metabolism and function in mice. J Mol Cell Cardiol 2011; 51: 906-18.

4 Picatoste B, Ramírez E, Caro-Vadillo A, Iborra C, Ares-Carrasco S, Egido J, et al. Sitagliptin reduces cardiac apoptosis, hypertrophy and fibrosis primarily by insulin-dependent mechanisms in experimental type-Il diabetes. Potential roles of GLP-1 isoforms. PLoS One 2013; 8: 
e78330.

5 Connelly KA, Zhang Y, Advani A, Advani SL, Thai K, Yuen DA, et al. DPP-4 inhibition attenuates cardiac dysfunction and adverse remodeling following myocardial infarction in rats with experimental diabetes. Cardiovasc Ther 2013; 31: 259-67.

6 Johansen OE, Neubacher D, von Eynatten M, Patel S, Woerle HJ. Cardiovascular safety with linagliptin in patients with type 2 diabetes mellitus: a pre-specified, prospective, and adjudicated meta-ananlysis of a phase 3 programme. Cardiovasc Diabetol 2012; 11: 3.

7 Nogueira KC, Furtado M, Fukui RT, Correia MR, Dos Santos RF, Andrade $\mathrm{JL}$, et al. Left ventricular diastolic function in patients with type 2 diabetes treated with a dipeptidyl peptidase-4 inhibitor-a pilot study. Diabetol Metab Syndr 2014; 6: 103.

8 Hocher B, Sharkovska Y, Mark M, Klein T, Pfab T. The novel DPP-4 inhibitors linagliptin and BI 14361 reduce infarct size after myocardial ischemia/reperfusion in rats. Int J Cardiol 2013; 167: 87-93.

9 Chinda K, Palee S, Surinkaew S, Phornphtkul M, Chattipakorn S, Chattipakorn N. Cardioprotective effect of dipeptidyl peptidae-4 inhibitor during ischemia-reperfusion injury. Int J Cardiol 2013; 167: 451-7.

10 Wang X, Lu J, Khaidakov M, Mitra S, Ding Z, Raina S, et al. Aspirin suppresses cardiac fibroblast proliferation and collagen formation through downregulation of angiotensin type 1 receptor transcription. Toxicol Appl Pharmacol 2012; 259: 346-54.

11 Wang X, Khaidakov M, Ding Z, Mercanti F, Mehta JL. LOX-1 in the maintenance of cytoskeleton and proliferation in senescent cardiac fibroblasts. J Mol Cell Cardiol 2013; 60: 184-90.

12 Tang $M$, Zhang $W$, Lin $\mathrm{H}$, Jiang $\mathrm{H}$, Dai H, Zhang Y. High glucose promotes the production of collagen types I and III by cardiac fibroblasts through a pathway dependent on extracellular-signal-regulated kinase 1/2. Mol Cell Biochem 2007; 301: 109-14.

13 Huang J, Siragy HM. Regulation of (pro) renin receptor expression by glucose-induced mitogen-activated protein kinase, nuclear factorkappaB, and activator protein-1 signaling pathways. Endocrinology 2010; 151: 3317-25.

14 Madhyastha R, Madhyastha H, Pengam Y, Nakajima Y, Omura S, Maruyama M. NFkappaB activation is essential for miR-21 induction by TGF $\beta 1$ in high glucose conditions. Biochem Biophys Res Commun 2014; 451: 615-21.

15 Wang LP, Wang Y, Zhao LM, Li GR, Deng XL. Angiotensin II upregulates $\mathrm{K}_{\mathrm{ca}} 3.1$ channels and stimulates cell proliferation in rat cardiac fibroblasts. Biochem Pharmacol 2013; 85: 1486-94.

16 Choi C, Helfman DM. The Ras-ERK pathway modulates cytoskeleton organization, cell motility and lung metastasis signature genes in MDA-MB-231 LM2. Oncogene 2013; 33: 3669-76.

17 Cortez DM, Feldman MD, Mummidi S, Valente AJ, Steffensen B, Vincenti M, et al. IL-17 stimulates MMP-1 expression in primary human cardiac fibroblasts via p38 MAPK- and ERK1/2-dependent C/ EBP-beta, NF-kappaB, and AP-1 activation. Am J Physiol Heart Circ Physiol 2007; 293: H3356-65.

18 Fiaschi T, Magherini F, Gamberi T, Lucchese G, Faggian G, Modesti $A$, et al. Hyperglycemia and angiotensin II cooperate to enhance collagen I deposition by cardiac fibroblasts through a ROS-STAT3dependent mechanism. Biochim Biophys Acta 2014; 1843: 260310.

19 Copaja M, Venegas D, Aranguiz P, Canales J, Vivar R, Avalos Y, et al. Simvastatin disrupts cytoskeleton and decreases cardiac fibroblast adhesion, migration and viability. Toxicology 2012; 294: 42-9.

20 Schram K, Granguly R, No EK, Fang X, Thong FS, Sweeney G. Regulation of MT1-MMP and MMP-2 by leptin in cardiac fibroblasts involves Rho/ROCK-dependent actin cytoskeletal reorganization and leads to enhanced cell migration. Endocrinology 2011; 152: 2037 47.

21 Sassoli C, Chellini F, Pini A, Tani A, Nistri S, Nosi D, et al. Relaxin prevents cardiac fibroblast-myofibroblast transition via notch-1mediated inhibition of TGF- $\beta$ /Smad3 signaling. PLoS One 2013; 8: e63896.

22 Lee TM, Lin SZ, Chang NC. Membrane ER $\alpha$ attenuates myocardial fibrosis via RhoA/ROCK-mediated actin remodeling in ovariectomized female infarcted rats. J Mol Med (Berl) 2014; 92: 43-51.

23 Shi D, Li X, Chen H, Che N, Zhou S, Lu Z, et al. High level of reactive oxygen species impaired mesenchymal stem cell migration via overpolymerization of F-actin cytoskeleton in systemic lupus erythematosus. Pathol Biol (Paris) 2014; 62: 382-90.

24 Surma M, Handy C, Chang J, Kapur R, Wei L, Shi J. ROCK1 deficiency enhances protective effects of antioxidants against apoptosis and cell detachment. PLoS One 2014; 9: e90758.

25 Kröller-Schön S, Knorr M, Hausding M, Oelze M, Schuff A, Schell R, et al. Glucose-independent improvement of vascular dysfunction in experimental sepsis by dipeptidyl-peptidase 4 inhibition. Cardiovasc Res 2012; 96: 140-9.

26 Batchuluun B, Inoguchi T, Sonoda N, Sasaki S, Inoue T, Fujimura Y, et al. Metformin and liraglutide ameliorate high glucose-induced oxidative stress via inhibition of PKC-NAD(P)H oxidase pathway in human aortic endothelial cells. Atherosclerosis 2014; 232: 156-64.

27 Thakur S, Li L, Gupta S. NF-kB-mediated integrin-linked kinase regulation in angiotensin II-induced pro-fibrotic process in cardiac fibroblasts. Life Sci 2014; 107: 68-75.

28 Tang $\mathrm{M}$, Zhong $\mathrm{M}$, Shang $\mathrm{Y}$, Lin H, Deng J, Jiang $\mathrm{H}$, et al. Differential regulation of collagen type I and III expression in cardiac fibroblasts by AGEs through TRB3/MAPK signaling pathway. Cell Mol Life Sci 2008; 65: 2924-32.

29 Ferreira AJ, Shenoy V, Qi Y, Fraga-Silva RA, Santos RA, Katovich MJ, et al. Angiotensin-converting enzyme 2 activation protects against hypertension-induced cardiac fibrosis involving extracellular signalregulated kinases. Exp Physiol 2011; 96: 287-94.

30 Ares-Carrasco S, Picatoste B, Benito-Martin A, Zubiri I, Sanz AB, Sánchez-Niño MD, et al. Myocardial fibrosis and apoptosis, but not inflammation, are present in long-term experimental diabetes. Am J Physiol Heart Circ Physiol 2009; 297: H2109-19.

31 Ogata T, Miyauchi T, Sakai S, Takanashi M, Irukayama-Tomobe $\mathrm{Y}$, Yamaguchi I. Myocardial fibrosis and diastolic dysfunction in deoxycorticosterone acetate-salt hypertensive rats is ameliorated by the peroxisome proliferator-activated receptor-alpha activator fenofibrate, partly by suppressing inflammatory responses associated with the nuclear factor-kappa-B pathway. J Am Coll Cardiol 2004; 43: 1481-8.

32 Villarreal F, Epperson SA, Ramirez-Sanchez I, Yamazaki KG, Brunton LL. Regulation of cardiac fibroblast collagen synthesis by adenosine: roles for Epac and PI3K. Am J Physiol Cell Physiol 2009; 296: C1178-84.

33 Nakano H, Nakajima A, Sakon-Komazawa S, Piao JH, Xue X, Okumura K. Reactive oxygen species mediate crosstalk between NF-kappaB and JNK. Cell Death Differ 2006; 13: 730-7. 